This paper discusses the influence of Ibn-Khaldun's view on bistory on Tatar Islamic reformer and historian of the 19th century Shibabaddin Mardjani. The author argues that both thinkers from different epochs not only elaborate a new approach to study history, but also the new understanding of rationality. This new method of Islamic rationality was based on applying idjtibad of Muslim lawyers (fuqaba') in the field of bistorical traditions (akbbar).

Keywords: Ibn Khaldun, Mardjani, idjtibad, islab/reform, bistory, bistoriography. 


\section{ИСТОРИЯ КАК ИСЛАМСКАЯ \\ НАУКА: МАРДЖАНИ \\ И ИБН ХАЛДУН}

\section{Игорь Аленсеев}

ialxyv@gmail.com

DOI: http://dx.doi.org/10.24848/islmlg.09.01.02

В статье обсуждается влияние исторических взгляов средневекоһого мусульманского мьслителя Ибн Халдуна на татарского историка и религиозного реформатора ХIX 6. Шихабаддина Марджани. Автор вььбигает предположение, что оба мьглителя каждьй в сьоих условиях разрабатььанот не только новьй подход к изучению истории, но и новьии тип рачиональности. Эта новая исламская рациональность может быьть рассмотрена как результат переноса логических методов правового исследования (иджтихад) в сферу изучения исторических преданий.

Ключевые слова: Ибн Халдун, Марджани, иджтихад, ислах/реформа, история, историография.

B

мияние Ибн Хацдуна на Марджани неоднократно обсуждалось отечественными исследователями (Юсупов, 1979, 1981, 2005; Юзеев, 1992, 1998; Юзеев, Гимадеев, 2009, с. 28; Хабутдинов, 2013 и др.). Прежде всего обращалось внимание на то, что «Введение в историю» (ац-Мукаддима) Ибн Хацдуна и его «Книга притч и сборник сообщений» (Китаб ац-'ибар ва диван ац-мубтада' ва- -хабар) были ис-

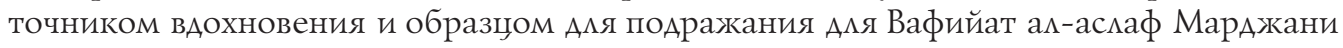
(Марджани, 1999, с. 5-6). Указывалось, что Марджани «в методологическом плане воспринял рационалистическую традицию Ибн Хамдуна» (Хабутдинов, 2013, с. 27). Отмечалось также вцияние идей Ибн Хацдуна на учеников Марджани (Хабутдинов, 2011).

Впервые наиболее подробно проблема идейного родства Авух мыслителей-историков была разработана М.Х. Юсуповым, который, в частности, отмечац, что:

по теоретическим вопросам исторической науки Марджани находился под влиянием идей крупнейшего историка XIV века и создателя новой для сбоей эпохи науки об истории Абд ар-Рахмана Ибн Халдуна <... .

Однако Марджани не только подражал этому мьслителю. Разделяя многие идеи Ибн Халдуна о предмете и роли исторической науки 8 теоретическом 
плане, Ш. Марджани редко прибегает кего данньм в источниковедческом аспекте, предпочитая первоисточники. Критическое отночение к первоисточникам, привлечение не только сведений письменньх традичий, но и данньх вещественных остатков, первье попьтки филологиеско$2 о$ анализа текста, строгое отношение к некоторьм видам повествовательных источников отличалот Марджани от Ибн Халдуна. Эта система взглядов напоминает <...> в какой-то мере скептическую школу в русской историографии (Юсупов, 1979, с. 13).

ОАнако в дальнейшем этот же исследователь утверждац, что МарАжани «многое <...> взял от Ибн Хамдуна и от многого из его наследия отказался» (Юсупов, 2005, с. 131).

Отличия Марджани от Ибн Хацдуна касаются, прежде всего, изцожения истории Средней Азии и Туркестана по средневековым арабоязычным источникам. Известно замечание, высказанное В.В. Бартольдом, о том, что данные Ибн Хацдуна (по истории Средней Азии. - И.А.) по большей части восходят к Ибн ал-Асиру, а оставшиеся «не всегда выдерживают критику» (БартольА, 1963, с. 48). Вслед за многими западными исследователями Ибн Халдуна раннего периода Бартольд в целом характеризовац автора Мукаддимы как оригинального мыслителя, который, однако, «в тексте самой истории» (Китаб ац-'ибар, введением к которой и является Мукаддима) остался «компилятором обычного типа» (Бартольд, 1966, с. 268). Марджани, как указывает Юсупов, обращается непосредственно к текстам Ибн ал-Асира и новейшим Аля своего времени источникам, таким как ал-Ажабарти (Юсупов, 2005, с. 132).

ОАнако это разцичие, безусловно важное с источниковедческой точки зрения, не кажется нам столь принципиальным с точки зрения общего подхода Ибн Хамдуна и МарАжани к историческому материалу по ряду причин.

Во-первых, само противопоставление Мукаддимы Ибн Хамдуна и “Ибар по степени оригинальности сегодня должно считаться устаревшим. Аля средневековой историографии компимяџия материала преАаний и хроник сама по себе представляет форму первичного исследования, а критерии отбора сведений для такой компицяџии - инструмент и метод средневекового историка. В средневековой арабской историографии с точки зрения современного исследователя представляет интерес не только фактическая достоверность материаца, но и метод его отбора, доступный автору круг источников и т.А. Как показал В.А. Кузнецов (2010), именно специфика такой селекции формирует нечто подобное историческому (и политическому) дискурсу в условиях отсутствия связного общепринятого нарратива.

Судя по всему, задачи применить теорию к эмпирическому материалу у Ибн Хацдуна не было - его «Введение» и есть теоретическое обобщение из компицятивного обзора Аоступной ему истории.

С Аругой стороны, Восток был, действительно, известен Ибн Халдуну хуже, чем Магриб, и он в большей степени зависец здесь от предшественников. ОАнако представляется, что оригинальность Марджани в рамках этого противопоставления также преувеличивается: он обращался к тем же источникам, что и Ибн Хацдун, работая с ними по тем же критериям истаким же инструментарием. Метод критики преАаний, сформулированный Ибн Халдуном, целиком поддерживался Марджани; список «авторитетных историков», заслуживающих доверия, у Марджани и Ибн Хацдуна в основе совпадает (Вакиди, Табари, ал-Хатиб ал-Багдади, среднеазиатский генеалог ас-Сам'ани 
(1113-1167)); сам этот метод критики - в основном отделение фантастических и явно недостоверных сведений от заслуживающих доверия и внимания. Речь вряд ми идет о проверке одних надежных источников Аругими, обсуждении позиџий и голосов авторов исторического нарратива.

Важно, однако, что в обоих случаях мы имеем дело с рационацизацией предания, своего рода "реформой» или «исправлением» истории, типологически сходной с «исправмением» (ислах) фикха. В последнем случае основным методом достижения искомой цели повсеместно в мусульманском мире было оживление иджтихада - раџиональной интерпретации норм шариата с учетом зАравого смысла, конкретно-исторических усмовий и с опорой на формализованные могические процедуры (от кийаса до ал-масалих ал-мурсала и макасид аш-шари'а). В современной историографии термин ислах закрепияся Аля обозначения преимушественно реформистских движений в исламе в Новое время, однако не будем забывать, что сама идея «исправления» на основе рационального целеполагания занимает важное место в дискурсе правоведов как минимум начиная с XI-XII вв. (Гасымов, 2015, с. 15-25; Гасымов, 2018). В XIV в. Ибн Хамдун преАложил метод рационального исследования истории как процесса и назвац его «новой наукой». Этим он произвел своего рода «иджтихаА» в историческом знании, переведя его из разряда традиционных наук в философские. Вместе с тем в правовой сфере, которая и была основной профессией Ибн Хацдуна, он оставацся на позиџиях мацикитского традиџионацизма, в то время как Марджани выступиц как реформатор и исламского права, и мусульманского (татарского) историописания.

$$
* * *
$$

$\triangle$

ействительно, историко-биографический свод татарского автора также открывается введением (мукаддима), в котором он приводит классификацию наук и дает обзор отраслей классического исламского знания. Как отмечал А.Н. Юзеев (Марджани, 1999, с. 5), в этой классификации «Марджани основывается на одной из шести частей книги Ибн Хамдуна (Мукаддима. - И.А.)».

Вслед за Ибн Халдуном (который, в свою очередь, опирается в этом отношении на предшествуюшую арабо-мусульманскую традицию) Марджани выделяет науки "рациональные», или «философские» ('аклийа/хикмийа), и «традиционные», или «установленные» (наклийа/вад'ийа):

«Науки, иметошие хождение в человеческой чивилизачии ('умран) разделяются на два вида: рациональнье ('аклийа)... и традиционнье (наклийа)» (Марджани, 1883, с. 210).

К первым относятся естественные науки, а также математика, могика и философия. Ко вторым - науки, основанные на изучении «предания» (хабар). Прежде всего это ремигиозные науки - хадис, тафсир, фикх, калам, - но также и схожие с ними по методу арабская филология ('улум ал-луга ал-'арабийа) и ее отрасли - грамматика, синтаксис, риторика и т.А. В число этих наук входит и 'илм ат-таßарих - историография, именно потому, что создание историй государств и народов основывается на исторических преАаниях (хабар):

«Кнаукам о язьке арабов (лисан ал-'араб) относятся... также история (тарих), генеалогия (ансаб) инаука о преданиях (ахбар)» (Марджани, 1883 , c. 252-253). 
Ранние исламские историографы вкмючали в число таких преданий и сообщения о словах и деяниях Пророка - хадисы, которые также часто назывались хабарами (см. напр. у Табари). При сборе, систематизации и оценке этих сообщений среАневековыми историографами использовались те же принџипы и методы, что и при сборе и оџенке хадисов. Гцавным из этих принципов явцяется изучение репутации передатчиков (руbam, еА.ч. рави) конкретных хабаров. Предания, исходившие от ненадежных передатчиков, обладавших плохой памятью, сомнительными мичными качествами, нечестностью и корыстолюбием, отклонялись. Аругие же, передававшиеся людьми с надежной репутацией, принимались как достоверные. Этот метод и основанная на нем вспомогательная субдисциплина традиционно называется 'илм ал-джарх ва-m-ma' дил.

Как известно, Ибн Халдун считал такой подход достаточным только для хадисов, имевших религиозное значение, и критиковац его использование историками:

[Историк] не должен прибегать канализу биографий рассказчиков преданий прежде, чем убедится В том, что описьваемое 6 самом сообщении могло или не могло бьть в приниипе. Если рассказанное невозможно, то нет пользи 8 подтверждении или опровержении биографии рассказчика. <...> Анализ биографий для подтверждения достоверности сообщения годится только для юридически значимьх предании, поскольку большинство ихявляютося установлениями, следование которьм Пророк вменил в обязанность при условии, что подтверждена их достоверность, а суждение о такой достоверности основььается на доверии к передатчику. Что же касается сообщений о собьттиях, то определить их достоверность можно прежде всего, установив соответствует ли сообщаемое [общему порядку вещей] и подтверждается ли внешними свидетельствами, а только потом - обрашаясь кличности рассказчика. Аля того же, чтобь установить это соответствие, и понять, бозможно или нет то, о чем сообщается, необходимо рассматривать человеческое общество (иджтима'), то есть чивилизачию ('умран). Изучая его в челом, мьь сможем определить, каковь его сущностнье особенности и какие характеристики и состояния обусловлень его природой, а какие - случайньи, несвойственнь и не могут быть придань ему. Таким образом мог сможем отличить в исторических преданиях истину от лжи. <...> Это знание является самостоятельной наукой о человеческом обшестве, со своим кругом проблем - наукой, последовательно облясняющей свойства и характеристики человеческого общежития (Ибн Хамдун, 1886, с. 33).

«История - это наука, великая с точки зрения пути, [которьм она идет], несушая огромную пользу и иметошая благородную иель. Поскольку она знакомит нас с состояниями ушедиих народов через их нравы, с пророками посредством описания ихжизни, а также сдинастиями иарей и их политикой, то для желаючего извлечь пользу из следования [историческим] примерам в делах верь (дин) и земной жизни (дунйа) необходимь многочисленнье источники и разнообразнье знания, а также способность к рассуждению и основательность, которье и приведут обладателя этих двух качесть кистине и уберегут от ошибок и заблуждений. Если же, имея дело систорическими преданиями, просто опираться на переданнье фактьи, не руководствуясь истоками [тех или иньх обьчаев], основами политики, [понятиями] природь иивилизачии и состояний человеческого общества, 
не сопоставлать скрьтое и явное, настоящее и уходащее, бынепременно оступитесь и свернете с пути истинь: многие историки, комментаторь Корана и передатчики уже допустили ошибки в своих рассказах, опираясь на простую передачу сведений, будь они прабдивьми или ложньми, не обрашаясь к их истокам, не сопоставляя схожие [случаи] и не применяя к ним мерило мудрости. Наконеи, онине имели понятия о природе Вещей, не избирали себе в правители рассуждение (назр) и умозрение (басира). Потомуто они и сошли с правильного пути, скитаясь [впоследствии] по пустььне заблуждений и ошибок» (Ибн Хамдун, 1886, с. 8-9; 2004, с. 21; 2008, с. 20).

Историк должен учитьљать основь политики, естественнье качества (таба'и') всего сущего, различия между народами, местностями и эпохами ८ том, что касается нрабов, обьчаеһ, религиозньх толков и школ, и других состояний (ахвал). Он должен также владеть современной ситуачией в этих областях, срабнивать настояшее с прошедшим, вьявляя сходства илистепень различия и обгяснать причинь этого. [Историку должнь бьгть известнь] происхождение и условия возникновения династий и религиозньх обшин, мотивь и причинь, вьзвавиие их кжизни, а также рассказь об их сторонниках. В конечном итоге он должен выяснить причинь каждого собьтия, узнать происхождение каждой истории. Затем необходимо проверить переданнье сообщения с помощью известньх ему законов и правил (кава'ид ва усул). Если предание им соответствует, оно истинно, если нет - нужно от него отказаться (Ибн Халаун, 1886:25; 2004, с. 47; 2008, c. 24).

Именно эти «правица и законы», принципы (усул; буквально - «основы», «корни») всемирно-исторического процесса и пытается сформулировать Ибн Хамдун в МукадАиме, переА тем как перейти к изложению притч (" $и б а р)$ и «рассказов о том, как было и что стало» (ал-мубтада' ва-л-хабар) «во Ани арабов, персов и берберов и их современников, обцадавших великой властью».

Таким образом, Ибн Хамдун настаивает на том, что в исследовании исторических сообщений использование здравого смысла и рациональной теории имеет явный приоритет перед формальными процедурами критики иснада - цепи передатчиков данного сообщения. Тем самым он переводит историю из числа наук «традиционных» в «рациональные» и вполне осознает революционный переворот, который им совершается. Поэтому он говорит, что создает «новую науку» - 'илм ал-' умран - «науку о человеческом общежитии/цивицизации», фактически, в современных терминах, - историческую социологию.

При этом методологическая революция Ибн Хамдуна оформияется в рамках характерного дия исламского дискурса тропа - новая наука описывается как возвращение к мудрости «праведных предков», утраченной последующими поколениями, погрязшими в невежестве:

Только поэтому древние историки признавали эту науку, да так, ито ей себя посвятили ат-Табари, ал-Бухари, а еще до них - Ибн Исхак и другие ученьье мусульманской уммь.. Но многие забьли ее секрет, и она стала глупьм занятием. Простолюдинь, не обладавиие прочньми знаниями, легко смотрели на исследование изнание истории, на ее глубокое изуче- 
ние как наспособ заработать. Пасущиеся без присмотра перемешались со стадом, зерна с шелухой, правдивьий слжеиом. Но исход всех дел - за Господом (Ибн Хамлун, 1886, с. 25; 2004, с. 47; 2008, с. 24).

Кроме того, использование термина усул (ед.ч. асл) указывает на то, что эта новая теоретическая дисциплина занимает по отношению к традиционной историографии такое же место, как теория исламского права (усул ал-фикх) по отношению к хадисоведению.

$$
* * *
$$

$\mathrm{M}$ арджани в своей Мукаддиме (Введении к Вафийат ац-аслаф) в некоторой степени воспроизводит композиционную и структурную цогику последней части (фасл) Мукаддимы Ибн Халдуна «О видах наук и способах обучения им». В тексте первого встречаются многократные парафразы и дословные цитаты из последнего, иногда с указанием источника, но чаще без всякой ссылки на своего великого предшественника. Вместе с тем татарский ученый очевидным образом использует не только риторику и фразеологию, но и терминологию магрибинца. В частности это касается кмючевого ибн-хацдуновского термина 'умран, вошедшего в название его «новой науки». Аискуссии о том, как наиболее адекватно может быть переведен этот термин, не утихают по сей день, однако однозначный вариант так и не найден. В западных переводах обычно используются термины, семантически связанные с идеей «цивилизации/ культуры», в русских - «человеческое общежитие» (Ибн Халдун, 1961) и даже «обустроенность» (Смирнов, 2008). Аля Марджани же, кажется, никаких проблем с пониманием этого термина не было. Как и Ибн Хацдун, он обозначает им совокупность форм устройства комлективной жизни мюдей, преимущественно характеризующегося высокой степенью сложности социальной организации.

В отличие от Ибн Халдуна, дмя которого, видимо, вполне очевидно место истории в ряду исламских наук, Марджани обосновывает ее мегитимность ссылками на Коран:

Об исторической науке говорит Всевьшний В Коране: «Вььведи народ твой из мрака на свет; напомни ему о днях Бога; потому ито В этом знамения для каждого терпеливого, благодарного!» (Коран, 14:5), «Бог хочет просвеmить вас и вести по путам тех, которье бьли прежде вас, бьть благопреклонньмм к Вам каюоимся: Бог знаюои, мудр» (Коран, 4:26) - то есть, напомнить вам том, что произоило с прежними народами... и указать вам на то, что вын не знаете, какие ваши деяния могут принести вам пользу и объяснить вам это (МарАжани, 1883, с. 265).

И сразу же после этого Почти Аословно воспроизводит оАу истории, с которой Ибн Хамдун начинает свое сочинение:

История - одна из тех наук, которье передают друг другу племена (аладжйал) и народь (ал-умам), стремится к ней всякий: и конньй, и пеший; ищет ее знаний базарньй люд и простонародье, состязаются 8 этом иари и вожди, она одинаково понятна ученьми и невеждам.

Внешняя сторона истории такова, ито она есть не более чем сообщение о собьтиях, династиях, о случивиемся в далекие времена, украшенное словами и поговорками. Она занимает переполненнье собрания [людей], сообщает нам о делах всего тьарного, об изменениях его состояний, о расшире- 
ниях грании и территорий [владений] династий, о том, как люди заселяли землю, пока не охватььвало их стремление покинуть ее или не настигала смерть.

Внутренная сущность истории - в рассуждении и исследовании, в тонком обгяснении причин всего сущего и его основ, в глубоком изучении образа свершения собьтий и их причин.

Именно поэтому история коренится в философии (хикма - букв. «муарость». - И.А.) и достойна сиитаться одной из ее наук (Ибн ХалАун, 2004, с. 12).

ОАнако завершает Марджани эту ибн-хацдуновскую цитату несколько иначе:

Именно поэтому ее (эту науку) назььают не только универсальной школой (ал-мадраса ал-куллийа), но и, действительно, матерью всех наук и познаний (умм ал-'улум Ва-л-ма'ариф) (Марджани, 1883, с. 265).

Возможно, конечно, мы имеем здесь дело с макуной, образовавшейся при типографском издании, и в оригинальном рукописном тексте в этом месте присутствовацо слово «мудрость» или что-то подобное. ОАнако даже если это и так (а скорее всего, это не так, потому что синтаксис арабского текста не очень подАерживает эту гипотезу), очевидно, что Марджани считает историю не просто одним из ответвлений философии или частью «мудрости», но утверждает, что она и есть сама универсальная мудрость и основа всякого знания.

Это наблюдение кажется нам важным потому, что историзм является одним из основополагающих эпистемологических принципов модерна. В начале XX в. в Ажадидской историографии сложился образ МарАжани как основоположника или предшественника татарского религиозного и научного модернизма. Этот образ был развит и окончательно закреплен казанскими исследователями в конце XX - начале XXI вв. С учетом того характера, который, судя по тексту самого МарАжани, имеет на него влияние Ибн ХалАуна, этот образ приобретает некоторые новые оттенки. Марджани выглядит не просто последователем Ибн Хамдуна, который применил некоторые его идеи, касающиеся рационального толкования исторических преданий, - и это открыло путь современной критической науке. Фактически Марджани оказывается буквально «татарским Ибн ХалАуном» - фигурой на стыке эпох, культур и мировоззрений, носителем традиционного домодерного знания в предАверии модернистского научного критиџизма и скептицизма. Обладая энџиклопедической эрудицией и будучи глубоко погруженным в интелмектуальный мир исламского знания, Марджани, в отличие от многих Аругих мусульманских модернистов, не интерполирует категории Нового времени, переводя их на язык исламского дискурса, а, напротив, выводит эпистемологические основания своего исторического подхода непосредственно из исламской традиции мудрости, которую в данном случае персонифицирует фигура Ибн Хамдуна. 


\section{ИСТОЧНИКИ И ЛИТЕРАТУРА}

Ибн Халдун. (1886). Ал-Мукаддима ли-'аллама Ибн Халдун. Бейрут: Матба'а адабийа.

Ибн Хамдун. (1961). Введение (фрагменты)/Пер. С.М. Бациевой. В: Избранньсе произведения мьслителей стран Ближнего и Среднего Востока IX-XIV 66. Москва: Соџэкгиз. C. $559-628$.

Ибн Хамлун. (2004). Мукаддимат Ибн Халдун. ац-Кахира: Аар ац-ФаАжр ми-т-турас.

Ибн Халдун. (2008). Введение в историю (ал-Мукаддима). Фрагменты./Пер. с араб., комм. и примеч. И.А. Алексеева, А.В. Аушак и А.Ш. Столыпинской. Pax Islamica, 1, 15-31.

Марджани Ш. (1883). Китаб вафийат ал-аслаф ва тахийат ал-ахлаф. (Электронный pесурс. Режим доступа: <URL:https://libweb.kpfu.ru/rare_books/east/1830-XIX/3729ar. pdf>. Аоступ: 20.08.2019, 00:17)

Марджани Ш. (1999). Вафият ал-аслаф ва тахият ал-ахлаф (Подробное о предшественниках и приветствие потомкам)/Пер. с араб., комм., вступ. ст. и примеч. А.Н. Юзеева. Казань: Иман.

Бартольд В.В. (1963). Туркестан 8 эпоху монгольского нашествия. Сочинения. Т. 1. Москва: Наука.

Бартольд В.В. (1966). Мусульманский мир. В: Сочинения. Т. 6. Москва: Наука. С. 207-297.

Гасымов К. (2015). Вместо введения. Теория ценей исламского права (макасид ащшари'а) в интерпретации мусульманских реформаторов. В: Ауда Аж. Цели шариата: руководство для начинаюших. Москва: ИА Марджани, 2015. С. 7-116.

Гасымов К. (2018). ИАжтихаА в свете целей шариата: Этико-правовая теория Ажассера Ауды. Islamology, 8(2), 9-28. doi:http:/ /dx.doi.org/10.24848/islmlg.08.2.01

Кемпер М. (2008). Суфии и ученьце 6 Татарстане и Баикортостане. Исламский дискурс под русским господстьом/Пер. с нем. И.А. Гицязов. Казань: Российский исламский университет.

Крачковский И.Ю. (1957). Арабская географическая литература. Избраннье сочинения. Т. 4. Москва-Иенинград: Издательство АН СССР.

Кузнецов В.А. (2010). ЕАинство и множественность мира в арабо-мусульманских историко-политических дискурсах X-XV веков. В: Репина А.П. (реА.) Образы времени и исторические предстабления: Россия - Восток - Запад. (С. 502-537). Москва: Кругъ.

Смирнов А.В. (2008). Ибн Хамаун и его новая наука. В: Историко-философский ежегодник 2007. С. 159-186. Москва: Наука.

Хабутдинов А.Ю. (2011). Ибн Халдун и Хусаин Фаизханов: методология исторической науки и анализ современности. Фаизхановские итения, 8. (Электронный ресурс. Режим Аоступа: <http://www.idmedina.ru/books/materials/?5098> 20.08.2019, 00:17.)

Хабутдинов А.Ю. (2013). Институтьь российского мусульманского сообщества в ВолгоУральском регионе. Москва: ИА МарАжани.

Юзеев А.Н. (1992). Мировоззрение Ш. Марджани и арабо-мусульманская философия. Казань: ИЯАИ.

Юзеев А.Н. (1998). Татарская философская мьсль кониа XVIII-ХIХ веков: эволюиия, основные направления и предстаһители. Казань: Иман.

Юзеев А.Н., Гимадеев И.Ф. (2009). Марджани о татарской элите. Москва: ИА МарАжани.

Юсупов М.Х. (1979). Шигабутдин Марджани как историк. Автореферат диссертации на соискание ученой степени кандидата исторических наук. Казань (на правах рукописи).

Юсупов М.Х. (1981). Шигабутдин Марджани как историк. Казань: Татарское книжное ИзА-во.

Юсупов М.Х. (2005). Шигабутдин Марджани. Казань: Татарское книжное изА-во. 


\section{REFERENCES}

Ibn Khaldun. (1886). Al-Muqaddima li-állama Ibn Khaldun. Beirut: Matbáa adabiyya.

Ibn Khaldun. (1961). Vvedenie (fragmenty)/per. S.M. Batsievoy. V: Izbrannye proizvedeniya mysliteley stran Blizhnego i Srednego Vostoka IX-XIV vv. (S. 559-628). Moska: Sotsekgiz (in Russian).

Ibn Khaldun. (2004). Muqaddimat Ibn Khaldun. al-Qahira: Dar al-Fajr li-t-turath.

Ibn Khaldun. (2008). Vvedenie v istoriyu (al-Muqaddima). Fragmenty./Per. s arab., komm. i primech. I.L. Alekseeva, A.V. Dushak i A.Sh. Stolypinskoy. Pax Islamica, 1, 15-31 (in Russian).

Marjani Sh. (1883). Kitab wafiyat al-aslaf va tabiyat al-ablaf. (<URL:https:/ libweb.kpfu. $\mathrm{ru} /$ rare_books/east/1830-XIX/3729ar.pdf> 20.08.2019, 00:17)

Marjani Sh. (1999). Wafiyat al-aslaf va tabiyat al-ablaf = Podrobnoe o predshestvennikab $i$ privetstvie potomkam/Per. s arab., komm., vstup. st. i primech. A.N. Yuzeeva. Kazan': Iman (in Russian).

Bartold V.V. (1963). Turkestan v epobu mongol'skogo nashestviya. Sochineniya. T.1. Moskva: Nauka (in Russian).

Bartold V.V. (1966). Musul'manskiy mir. Sochineniya. T.6. Moskva: Nauka. (S. 207-297) (in Russian).

Gasymov K. (2015). Vmesto vvedeniya. Teoriya tseley islamskogo prava (makasid ash-sharía) v interpretatsii musul'manskih reformatorov. V: Auda Dzh. Tseli shariata: rukovodstvo dlya nachinayushchib. Moskva: ID Mardzhani, 2015. S. 7-116 (in Russian).

Gasymov K. (2018). Idzhtihad v svete tseley shariata: Etiko-pravovaya teoriya Dzhassera Audy. Islamology, 8(2), 9-28. doi:http:/ /dx.doi.org/10.24848/islmlg.08.2.01 (in Russian).

Habutdinov A.Yu. (2011). Ibn Khaldun i Husain Faizhanov: metodologiya istoricheskoy nauki i analiz sovremennosti. Faizhanovskie chteniya, 8. (<http://www.idmedina.ru/books/ materials/?5098> 20.08.2019, 00:17) (in Russian).

Habutdinov A.Yu. (2013). Instituty rossiyskogo musul'manskogo soobshchestva v VolgoUral'skom regione. Moskva: ID Mardzhani (in Russian).

Kemper M. (2008). Sufii i uchenye v Tatarstane i Bashkortostane. Islamskiy diskurs pod russkim gospodstvom/Per. s nem. I.A. Gilyazov. Kazan': Rossiyskiy islamskiy universitet (in Russian).

Krachkovskiy I.Yu. (1957). Arabskaya geograficheskaya literatura. Izbrannye sochineniya. T.4. Moskva-Leningrad: Izdatel'stvo AN SSSR (in Russian).

Kuznetsov V.A. (2010). Edinstvo i mnozhestvennost' mira v arabo-musul'manskih istorikopoliticheskih diskursah X-XV vekov. V: Repina L.P. (red.) Obrazy vremeni i istoricheskie predstavleniya: Rossiya - Vostok - Zapad. Moskva: Krug. S. 502-537 (in Russian).

Smirnov A.V. (2008). Ibn Khaldun i ego novaya nauka. V: Istoriko-filosofskiy ezhegodnik 2007. Moskva: Nauka. S. 159-186 (in Russian).

Yusupov M.H. (1979). Shigabutdin Mardzhanikak istorik. Avtoreferat dissertatsii na soiskanie uchenoy stepeni kandidata istoricheskih nauk. Kazan' (na pravah rukopisi) (in Russian).

Yusupov M.H. (1981). Shigabutdin Mardzhani kak istorik. Kazan': Tatarskoe knizhnoe izdatel'stvo (in Russian).

Yusupov M.H. (2005). Shigabutdin Mardzhani. Kazan': Tatarskoe knizhnoe izdadel'stvo (in Russian).

Yuzeev A.N. (1992). Mirovozzrenie Sh. Mardzhani i arabo-musul'manskaya filosofiya. Kazan': IYaLI (in Russian).

Yuzeev A.N. (1998). Tatarskaya filosofskaya mysl'kontsa XVIII-XIX vekov: evolyutsiya, osnovnye napravleniya i predstaviteli. Kazan': Iman (in Russian).

Yuzeev A.N., Gimadeev I.F. (2009). Mardzhani o tatarskoy elite. Moskva: ID Mardzhani (in Russian). 